\title{
Dropout and narcissism: an exploratory research about situational factors and personality variables of the psychotherapist
}

\author{
Osmano Oasi, Simone Maggio, Sara Pacella, Sara Molgora \\ Department of Psychology, Catholic University of Sacred Heart, Milan, Italy
}

\begin{abstract}
The premature interruption of psychotherapeutic treatments is a significant phenomenon, with rates that can be above $50 \%$, although differences emerge among studies. In general, the variables related to the psychotherapists have a significant effect on the treatment and a greater extent than the situational variables. In this study a multi-method research has been conducted to test the situations of impasse ending in dropout and the relationship between these situations and the covert narcissistic dimension of the therapist. Each participant was administrated the Impasse Interview, asking the therapist to focus on a salient or recent dropout case, and the Hypersensitive Narcissism Scale. The linguistic analysis of the interviews carried out with T-Lab produced 4 thematic clusters. Furthermore, as for the covert narcissistic dimension, 11 therapists reported a score below the average (Group A) and 9 scoring in the average (Group B). Finally, the association between the four clusters and the two groups of therapists was investigated. The therapeutic alliance and the emotional reaction of the therapist, influenced by his narcissistic dimension, represent key variables for the outcome of the therapy.
\end{abstract}

Key words: Dropout; Psychotherapist variables; Narcissism covert.

Correspondence: Osmano Oasi, Department of Psychology, Catholic University of Sacred Heart, Largo A. Gemelli 1, 20123 Milan, Italy.

Tel.: +39.02.72342688 - Fax: +39.02 .72342280 .

E-mail: osmano.oasi@unicatt.it

Acknowledgments: the authors are grateful to all the colleagues who are involved in their research.

Citation: Oasi, O., Maggio, S., Pacella, S., \& Molgora, S. (2019). Dropout and narcissism: an exploratory research about situational factors and personality variables of the psychotherapist. Research in Psychotherapy: Psychopathology, Process and Outcome, 22(2), 165-174. doi: 10.4081/ripppo.2019.369

Contributions: $\mathrm{OO}$ and SMa produced the first draft of the final manuscript, tables and figures included. SP conducted the data collection. SMo conducted the analyses. OO revised the final version of the manuscript. All authors approved the final version of the manuscript.

Conflict of interest: the authors declare no potential conflict of interest.

Funding: none.

Received for publication: 9 January 2019.

Revision received: 31 March 2019.

Accepted for publication: 26 April 2019.

This work is licensed under a Creative Commons Attribution NonCommercial 4.0 License (CC BY-NC 4.0).

${ }^{\circ}$ Copyright: the Author(s), 2019

Licensee PAGEPress, Italy

Research in Psychotherapy:

Psychopathology, Process and Outcome 2019; 22:165-174

doi:10.4081/ripppo.2019.369

\section{Introduction}

Like in pharmacotherapeutic treatments also in psychotherapies side effects are detected. Of course, the side effects are considered unwanted effects and the highest effort could be done in avoiding them. Curiously, the scientific literature about this topic suggests that the amount of unwanted effects of psychotherapies and of pharmacotherapies is very similar and ranges between $3 \%$ and $15 \%$ of cases (Berk \& Parker, 2009; Boisvert \& Faust, 2006; Jarrett, 2007; Mays \& Franks, 1985; Mohr, 1995; Moos, 2005; Roback, 2000). In order to identify the variables involved in negative process treatment, the distinction drawn by (Linden, 2013) among the unwanted events (UE) is useful. He distinguishes the treatment-emergent reactions (referred to any UE caused by the treatment); the adverse treatment reactions (referred to any UE that is probably caused by correct treatment); the malpractice reaction (referred to any UE that is probably caused by incorrect or improperly applied treatment); the treatment non-response (referred to the lack of improvement in spite of treatment); the deterioration of illness (referred the worsening of the illness during therapy or any other time in the course of illness). These are events that can be determined either by the patient or by the therapist or by their interaction.

More specifically, looking into the psychotherapeutic treatments the occurrence of premature terminations or dropout cases is a fundamental issue, both in terms of the management of the clinical services dedicated to mental health and in terms of the evaluation of treatment effective- 
ness and its cost-benefit ratio (Garfield, 1986; Pekarik, 1985). In a first important comprehensive review published in 1993, Wierzbicki and Pekarik have shown that the average dropout rate across 125 studies was $47 \%$. More recently, the meta-analytic study of Swift and Greenberg (2012) has suggested that approximately one in every five clients still chooses to end treatment prior to its completion of psychotherapy. Even if a lower rate than what was estimated 20 years ago was found, the premature discontinuation and dropout are still a significant problem.

While the effectiveness of psychological and psychotherapeutic treatment has been solidly confirmed by numerous studies (Kazdin \& Weiss, 2003; Nathan \& Gorman, 1998, 2007; Roth \& Fonagy, 1996, 2004), the same attention hasn't been given to the negative outcomes of psychotherapy or to unsuccessful psychotherapies. An analysis of the literature (Atwood, Stolorow, \& Trop, 1989; Elkind, 1992; Grunebaum, 1986; Mordecai, 1991; Nathanson, 1992; Newirth, 1995; Omer, 1994; Pulver, 1992; Stein, 1972; Strupp, 1993; Taylor, 1984; Watkins, 1983; Weiner, 1974) gives an idea of the factors associated with the impasse at a more general level. Hill, NuttWilliams, Heaton, Thompson, and Rhodes (1996) and, more recently, Kächele and Schachter (2014), tried to aggregate them. A summary of these factors is presented below (in italics character are the key words of each factor to be considered). When referring to the patient we can consider: his pathology and diagnosis, which prevents him from being able to benefit from the treatment and the consequent administration of an unsuitable treatment; his constitutional factors and unwanted changes from his Ego with relapses in terms of personality disorder; his feelings, for example shame in addressing some issues related to cultural reasons. It should be noted that we are dealing here within descriptive psychopathological factors. On the other hand, when referring to the therapist we can consider: his countertransference or personal issues that interfere with their ability to adequately deliver therapy; patient transference perceived by the therapist or inappropriate gratification given to the patient and, in general, aspects related to transference and countertransference; errors of the therapist such as a wrong diagnosis, actingout, inappropriate interventions, collusion, pejorative communication or even the non-recognition of the goals achieved or reachable by the patient. These factors seem attributed in some way to the psychodynamic framework and are the background of emerging unsolved relationship problems of the therapist in impasse cases. Finally, we have to take into consideration some trans-theoretical factors such as real issues related to the situation or external, for example the death of a relative; the contrasts between patient and therapist caused by the respective periods of life, different personalities, theoretical orientation or ultimately personal issues and preferences; some problematic aspects of the therapeutic relationship, for example a rigid or unrecorded relationship or an infringement in the at- tachment bond; the failure to agree on the goals of the therapy or a failure in the communication of the same.

We would like to highlight that some of these latter factors are important aspects of construction of the therapeutic alliance. As detailed by Swift, Spencer and Goode (2018), one of the more implicated concepts in the unsuccessful psychotherapies is the therapeutic alliance and, in particular, the therapist's ability to repair alliance rupture when they occur. In other words, the age, the level of antisocial behavior, the level of intelligence (O'Keeffe et al., 2018) or the intrapsychic functionality (Rubin, Dolev, \& Zilcha-Mano, 2018) are certainly implicated in the premature termination of the treatment, but not in a unique way. The possibility to distinguish temporary rupture sessions from the dropout sessions referring to the amount and variety of the session content, the type of ruptures that occurred, and the frequency of positive therapist behavior (Soygüt \& Gülüm, 2016) seem more useful than the variables pointed out above. On the other hand, different meta-analytic studies (Flückiger, Wampold, \& Horvath, 2018; Horvath, Del Re, Flückiger \& Symonds, 2011; Horvath \& Symonds, 1991) have confirmed the robustness of the positive relationship between the alliance and outcome, and its displacement, more and more clear, from the patient to the psychotherapist. The challenge is to define in a fit way the variables coming from the psychotherapeutic part that represent mediation factors referring to alliance construction (Safran \& Muran, 1998).

Returning to the factors related to the therapist, we believe important to take into account not only his countertransference or emotional reaction to the communication or to the behavior of the patient (Heinonen \& Nissen-Lie, 2019), but also some specific personality traits. In this perspective, Stone (1961) provided a suggestive example when he has observed that some classical recommendation of the psychoanalytic tradition - as a famous metaphor of the mirror referring the abstinent rule - could be in perfect agreement with passive-aggressive or compulsive trait of the psychotherapists.

Indeed, the power and the efficacy of the classical techniques are influenced in-depth by the earlier dispositions of the psychotherapist. Some years ago, Henry and Strupp (1994) has shown that the presence of particular personality dimensions, such as the one denominated disaffiliated and hostile, could influence the building of the relationship between patient and the psychotherapist. Referring a previous study of Frayn (1992), the authors underline that an attitude or a feeling based on fear, preoccupation or hostility in the psychotherapist enhances the premature termination of treatment or dropout cases. Finally, following Miller when she has affirmed that the narcissistic dimension is one of the main personality features in health workers like that of the psychotherapist (Miller, 1979, 2008), we suppose that trying to help others gives one the sense of gratification to the Ego of those who provide that help. The narcissistic trait can be con- 
sidered as support referred to health workers like future psychotherapist (Stella \& Oasi, 1996), but also as an implicated variable in job burnout (Schwarzkopf et al., 2016). In our opinion, the therapeutic failures are an event that can test the therapist's narcissistic integrity. On the other hand, a high level of narcissism could harm good empathic attitude. We know that this data is empirically founded for clinical samples (e.g., Ritter et al., 2011), but we also know that if the psychotherapist has an empathetic approach in relationship to the patient, he/she is sure that the psychotherapeutic work presents a basic element for developing the process of care in a suitable way. Kohut (1982) supports us in this opinion. These considerations thrust us to keep in considering the narcissistic dimension of the therapist's personality in the present research.

\section{Methods}

\section{Research aims}

The aims of the present study were: i) to investigate the main themes reported by the therapists when they talk about their experience on psychotherapy dropout and the possible correlation between therapist's narcissistic dimension and psychotherapeutic failures; ii) to analyze whether the therapists' language changes according to some personal (therapist's narcissism) and professional (therapist's orientation) characteristics as well as some dimension related to the therapeutic process (method of interruption; therapist's feeling about dropout).

\section{Research hypothesis}

Specifically, two main hypotheses have been formulated: i) is there an association between the construction of a good therapeutic alliance and the failure of the psychotherapy, starting from therapist's point of view? ii) is there an association between the (covert) narcissistic personality style of the therapist and the therapeutic failure?

\section{Steps of research}

2018, February - March. Participants recruitment.

2018, May - April. Conducting interviews and data collection.

2018, June - July. Data analysis.

\section{Sample recruitment}

The participants in this research were recruited through 3 methods: i) informal contact network; ii) web search engines, websites that aggregate profiles of mental health professionals such as psychologists and psychotherapists: https://www.psicologi-italia.it/ and https://www.guidapsicologi.it/; iii) social networks: https://www.facebook.com/ and https://www.linkedin.com

The participants were contacted both by telephone and by e-mail address. Later, an email was sent to the thera- pists contacted by telephone with the request of participating in the research with an interview de visu. For the others, the e-mail was sent directly with the request of participation. To avoid possible bias, detailed information on the research design was provided at the end of the meeting. Before the interview, each participant was asked to sign the informed consent form and was asked to record the audio of the interview. All the participants agreed to both requests. At the end of the interview, each participant was asked to fill in a self-report questionnaire.

\section{Sample of therapists}

The sample consists of a total of 20 psychologists psychotherapists, where there are 14 female and 6 male; all participants were of Italian nationality. The average age is 43.4 years $(\mathrm{SD}=5.51)$ with a range of 34 to 58 years. All recruited participants are registered in the professional register of psychologists and have been annotated in the Register of Specialization in Psychotherapy for at least 5 years. The general sample is composed of 3 subgroups that differ according to the psychotherapeutic orientation: group 1 is formed by psychodynamic psychotherapists $(\mathrm{N}=6)$, group 2 by cognitive-behavioral psychotherapists $(\mathrm{N}=6)$, and group 3 by psychotherapists of other orientations (i.e., humanistic orientation or integrative strategic orientation) not related to the first two $(\mathrm{N}=8)$.

\section{Dropout cases}

The sample of patients examined in this survey and whose personal therapy ended with a dropout is of 20 subjects; of these 11 are female and 9 of male gender. Compared to the diagnosis, referring to the DSM-IV TR, 10 patients had a symptomatology attributable to Axis I, 9 patients to a disorder attributable to Axis II. For all patients the setting was the private study.

The average number of weekly sessions provided is 0.95; the number of sessions delivered ranges from 2 to 120 sessions (median $=27 ; \mathrm{M}=36.6 ; \mathrm{SD}=31.57$ ) for a period ranging from 0.5 to 30 months (median=7, $M=11.75$, $\mathrm{SD}=9.07)$. Sessions characterized by an impasse situation range from 0 to 30 (median=6; $\mathrm{M}=7.3 ; \mathrm{SD}=7.45$ ).

\section{Instruments}

\section{Impasse interview}

Hill et al. (1996) have formulated The Questionnaire on Impasse into Individual Therapy, a self-report tool to compile paper and pen, developed from a review of the literature on stalemates in psychotherapy and from the Rhodes, Hill, Thompson, and Elliott questionnaire (1994). The questionnaire retrospectively investigates a salient or recent case that occurred to the terminated therapist. The questionnaire consists of 4 sections: i) general information about the therapist, regarding his training and his psychotherapeutic orientation; ii) general information on the situations of impasse experienced by the therapist; iii) 
general information about the patient involved in recent or salient impasse situation; iv) in-depth analysis of the impasse with the chosen patient.

The definition of impasse proposed to the therapists was that of a situation of difficulty or stalemate that leads the therapy to become so difficult and complicated as to make it impossible to progress and to cause an interruption. Furthermore, the impasse situation was accompanied by feelings of anger, disappointment or sense of failure on the part of the therapist or patient.

For the present study, the questionnaire by Hill et al. (1996) was translated into Italian, revised by a graduate of Psychology and an English mother tongue, and culturally adapted into the Italian context. The original questionnaire was then reshaped into a structured interview with the same 4 thematic sections; no questions have been added or deleted from the Hill et al. (1996).

\section{Hypersensitive Narcissism Scale}

Hendin and Cheek (1997) have developed the Hypersensitive Narcissism Scale (HSNS) starting from the correlations between the H. A. Murray Narcissism Scale (Murray, 1938) and the compound measure of the hyper vigil (covert) narcissism of the Minnesota Multiphasic Personality Inventory (MMPI). The HSNS is a self-report tool composed of 10 items on the Likert scale $(1=$ not at all, $5=$ very typical) that then specifically investigates aspects of the narcissistic personality on the vulnerable side; from the statistical analysis it was found to have a good internal reliability (Cronbach $\alpha=0.7$ ). The Italian translation of the instrument (Fossati et al., 2009) was validated both on a clinical sample $(\mathrm{N}=366)$ and on a non-clinical sample $(\mathrm{N}=385)$. The values of the HSNS test for the clinical sample were $\mathrm{M}=31.03, \mathrm{SD}=7.37$, while for the nonclinical sample were $\mathrm{M}=27.93, \mathrm{SD}=5.99$. The results also showed a substantial internal reliability (Cronbach $\alpha=0.71$ ) without gender differences for the clinical sample. In addition, for the non-clinical sample good reliability was shown (Cronbach $\alpha=0.69$ ).

\section{Data analysis}

The questionnaire was analyzed performing statistical analyzes with SPPS 22.0 for Windows (IBM, Armonk, NY). Descriptive, correlation, and post hoc analysis were performed.

The interview was audio-recorded and then transcribed electronically using an online transcription software and its application (transcribe.wreally.com). The transcriptions were subsequently supervised in analogue mode. The verbatim of the interviews was analyzed with T-LAB (version 7.3.0; Lancia, 2004), a word-driven Computer Assisted Data Qualitative Analysis Software (CAQDAS) that permit to perform several exploratory and interpretative analyses on the text to investigate its structure and meaning. Specifically, unlike a traditional paper-pencil content analysis, this mixed-method (i.e., quantitative and qualitative) textual analysis software consists of a set of linguistic, statistical and graphical tools for the analysis of the text and create, through several algorithms, different kind of new data that represents a synthesis of the text and required to be interpreted by the researcher. Thus, this software improves the rigor and reliability of the analyses (Lancia, 2004). In particular, T-LAB allows the evaluation relations among words (i.e., lexical units) within an entire text (i.e., the corpus), or within specific sections of the text (i.e., the elementary context - that is, the segmentation of the corpus automatically done by the software, or the context units - that is, the segmentation of the corpus done by the researcher on the basis of some independent variables). In this study, the corpus was composed by 20 interviews. Before starting the evaluations, the corpus needs to be cleaned, following the rules of cleaning and adaptation of the text, as foreseen by the developers of the software. For the aims of this study, sections 3 and 4 of each interview were used, i.e. those that concerned the chosen case of dropouts in its general aspects and then specific with respect to what happened. Specifically, three different analyses were performed: the thematic analysis of elementary context, the correspondence analysis and the specificity analysis.

The thematic analysis of the elementary contexts allows to build a representation of the corpus content through the identification of significant thematic clusters (from a minimum of 3 to a maximum of 50): each cluster consists of a set of elementary contexts (i.e., sentence or paragraph) characterized by the same keywords patterns and is described through the lexical units and variables that most characterize the elementary contexts of which it is composed. The result of these analyzes allows a mapping of general or specific themes characterized by the co-occurrence of semantic traits.

The correspondence analysis allows to detect the similarities and the differences among the context units; in particular with respect to the words for categories of a variable with occurrence values. Similar to factor analysis, this analysis extracts a set of new variables (i.e., factors), each of them setting up a spatial dimension on the negative and positive endpoints: the elements (levels of variables and words) that are placed on opposite ends of the factor are most different from each other.

Finally, the specificity analysis allows the identification which lexical units are typical (i.e., statistically overused) or exclusive in a portion of the corpus identified by a categorical variable. Both the correspondence analysis and the specificity analysis are comparative analyses that allow to make a comparison among different segments of the corpus: the first one is possible only with variables that have at least three levels, while the second one can be performed also with two level variables. In our study, these following independent variables were examined: i) orientation of the therapist: psychodynamic, cognitive-be- 
havioral and other orientations (three levels); ii) method of interruption of treatment: de visu (communicated during a session), mediated (through a telephone communication or with a mobile phone message) and none (interruption occurred without communication) (three levels); iii) therapist's feelings regarding the dropout: anger, sense of impotence/relief/sadness (four levels); iv) therapist's narcissism: group A (below the average) and group B (on the average) (two levels).

\section{Results}

\section{Hypersensitive Narcissism Scale}

The therapist sample was divided into two groups using as a parameter the value Test emerging from an Italian validation of the instrument (Fossati et al., 2009). The mean of the general sample was $20.75(\mathrm{SD}=5.69)$. Compared to the normative data of the non-clinical sample no therapist reported above average values $(\mathrm{M}=27.93$, $\mathrm{SD}=5.99)$. The general sample was then divided into the 2 subgroups (A and B): group A was formed by the therapists who reported a score below the normative average $(\mathrm{N}=11)$ and group $\mathrm{B}$ composed by the therapists with scores in the normative average $(\mathrm{N}=9)$. Group A (Low Narcissism) were assigned the therapists who reported a score lower than $1.94(\mathrm{M}-1 * \mathrm{SD})$ and group B (Mean Narcissism) the therapists with a score included in Mean value \pm SD.

\section{Cluster analysis}

The thematic analysis of the elementary contexts with the use of the measure of the cosine through the bisecting method K-means (Savaresi \& Booley, 2001; Steinbach, Karypis, \& Kumar, 2000), implemented on the whole corpus of the 20 interviews, produced a 4 thematic cluster solution.

\section{Cluster 1}

Cluster 1, labeled Working Processes of Therapy, aggregates 92 elemental contexts of the 508 classifieds, which correspond to $18 \%$ of the variance (Table 1). Some of the main lemmas of this cluster are: to work, effort, to make a mistake, frustration, relationship, bill. Those lemmas seem to refer specifically to the aspects of the therapist's work; in particular to the difficulties made known during the therapy.

\section{Cluster 2}

Cluster 2, labeled Therapist's subjective experience, aggregates 154 elemental contexts of the 508 classifieds, which correspond to $30 \%$ of the variance (Table 1). From this cluster it seems to emerge issues related to personal experience of the therapist linked to the therapy, in particular it highlights both negative emotional experiences and perceptions. Therefore, the cluster is characterized by terms such as: to feel, anger, to betray, to mistreat, to forget, coping, own, and to get involved.

Table 1. Thematic analysis: lemmas and variables.

\begin{tabular}{|c|c|c|c|c|c|c|c|}
\hline \multicolumn{2}{|l|}{ Cluster $1(18 \%)$} & \multicolumn{2}{|c|}{ Cluster $2(30 \%)$} & \multicolumn{2}{|c|}{ Cluster 3 (25\%) } & \multicolumn{2}{|c|}{ Cluster 4 (27\%) } \\
\hline Lemma & $\mathrm{CHI}^{2}$ & Lemma & $\mathrm{CHI}^{2}$ & Lemma & $\mathrm{CHI}^{2}$ & Lemma & $\mathrm{CHI}^{2}$ \\
\hline To work & 111.16 & Own & 40.88 & Average & 39.78 & Therapeutic_alliance & 57.02 \\
\hline To let go & 39.33 & To feel & 31.30 & Following & 23.96 & Good & 44.85 \\
\hline Features & 19.27 & Anger & 28.47 & Meaning & 23.40 & Desire & 21.88 \\
\hline interv_6 & 18.48 & To see & 22.24 & Supervision & 22.54 & Troubles & 21.88 \\
\hline Pregnancy & 15.71 & Struggle & 17.61 & To talk & 21.51 & Anxiety & 21.70 \\
\hline of_this_kind & 14.74 & Therapist's office & 15.46 & Situation & 20.61 & To function & 21.36 \\
\hline Themes & 14.74 & Collegue & 14.68 & House & 20.42 & To ask & 20.91 \\
\hline Moment & 14.21 & Get involved & 13.61 & Failure & 20.42 & Trust & 20.39 \\
\hline Relationship & 13.47 & Day & 13.25 & _interv_2 & 20.06 & Panic attacks & 15.04 \\
\hline Effort & 13.40 & To arrive & 12.45 & _diagnosis_axis1 & 19.66 & To trust & 15.04 \\
\hline To make a mistake & 11.77 & To betray & 11.83 & Memory & 18.33 & To follow & 14.45 \\
\hline Frustration & 11.32 & Friend & 11.04 & Missed & 18.06 & Fine & 13.67 \\
\hline Interruption & 11.32 & Coping & 11.04 & To learn & 16.91 & To solve & 12.40 \\
\hline _interv_19 & 10.81 & To forget & 11.04 & Dreams & 16.91 & Symptom & 12.40 \\
\hline Bill & 10.75 & To mistreat & 11.04 & Mistake & 16.69 & Drugs & 11.96 \\
\hline
\end{tabular}




\section{Cluster 3}

Cluster 3, labeled Managing impasse and dropout, aggregates 132 elemental contexts of the 508 classifieds, which correspond to $25 \%$ of the variance (Table 1 ). The third cluster seems to capture a different aspect of the therapist's experience with stalemate and disruptive situations; in particular the modalities with which the impasse and the subsequent dropout were tackled by the therapist. In this sense the most significant terms are: supervision, to talk, failure, diagnosis, to learn, mistake.

\section{Cluster 4}

Cluster 4, labeled Therapeutic alliance and relationship, aggregates 130 elemental contexts of the 508 classifieds, which correspond to $27 \%$ of the variance (Table 1). From this fourth and last cluster it appears to emerge the crucially of the theme and the aspects related to the construction of the therapeutic alliance (therapeutic alliance, good, to function) and in general of the therapeutic relationship (trust, to trust, troubles); in particular, the ambivalence and difficulty of managing the impasse are underlined. Finally, the presence in this cluster of terms such as drugs, symptom, anxiety, panic attack may refer to the influence on the therapeutic alliance of both the prescription of a pharmacological support and some symptomatic manifestations.

We proceeded with the analysis of the distribution of the 4 clusters among the different levels of the therapist's narcissism variable. Group A is explained for its 20\% variance from cluster $1,32.1 \%$ from cluster 2, 26.2\% from cluster 3 , and $21.7 \%$ from cluster 4 . With reference to Group B the variance is explained at $16.4 \%$ from cluster $1,28.7 \%$ from cluster $2,25.7 \%$ from cluster 3 , and $29.1 \%$ from cluster 4 .

\section{Correspondence analysis}

The correspondence analysis, aimed at comparing different segments of the corpus, was performed for the orientation of the psychotherapists, method of interruption of treatment and therapist's feelings regarding the dropout variables (test threshold value for significance \pm 1.96 ).

\section{Orientation of the therapist}

The correspondence analysis for the orientation variable showed two factors explaining respectively $52.23 \%$ and $47.77 \%$ of the data variance (Figure 1). With respect to the first factor (horizontal axis) the negative factorial polarity shows a test value for the cognitive-behavioral orientation of -29.06, referring lemmas such as difficulty, goal, challenge, and treatment. For the positive factorial polarity, the value of the test for the psychodynamic orientation is 17.52 and for others is 13.64, referring lemmas such as dynamic, need, countertransference, and disappointment. The correspondence analysis with respect to the vertical axis shows a test value for the psychodynamic orientation of -23.27 and cognitive-behavioral orientation is -7.05 for the negative factorial polarity, referring lemmas such as dynamic, patient, cbt, desire, and dependency. The test value for the others orientation is $\mathbf{2 5 . 5 3}$ for the positive factorial polarity, referring lemmas such as other, message, to end, and question.

\section{Method of interruption of treatment}

The correspondence analysis for the method of interruption of treatment variable showed two factors explaining respectively $52.62 \%$ and $47.38 \%$ of the data variance (Figure 2). With respect to the first factor (horizontal axis) the negative factorial polarity shows a test value for the no communication mode that is -23.12 and for the mediated

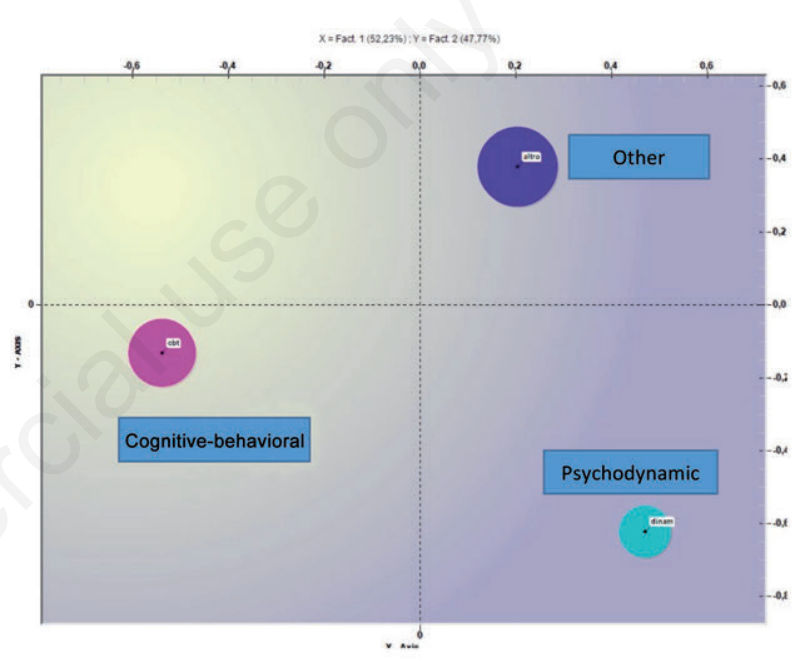

Figure 1. Correspondence analysis: orientation of the therapist.

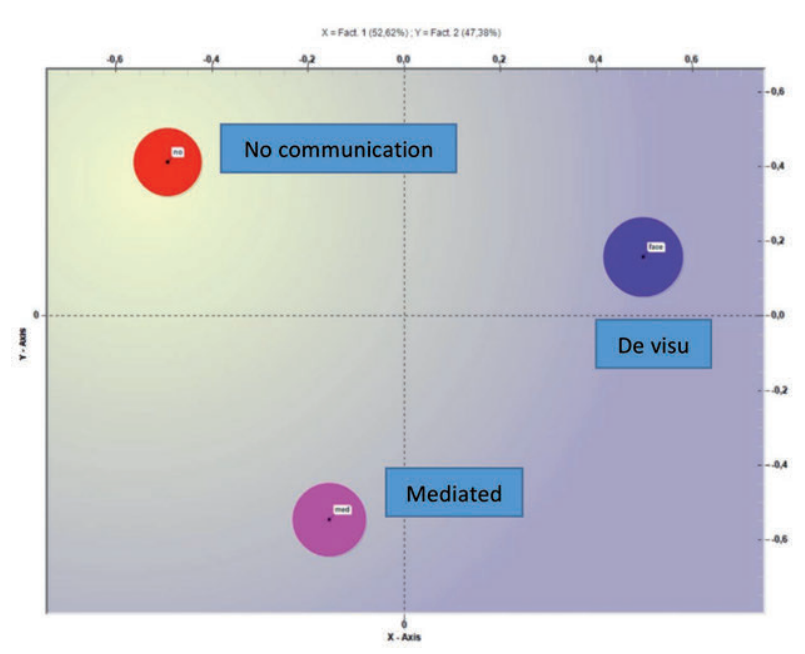

Figure 2. Correspondence analysis: method of interruption of treatment. 
mode is - 8.08 , referring lemmas such as you, goal, to betray, and to devalue. For the positive factorial polarity, the value of the test for the face-to-face mode is 29.24 , referring lemmas such as face, to happen, period, and reaction. With respect to the vertical axis, the negative factorial polarity produces a test value of -28.22 for the mediated mode, referring lemmas such as message, to see, personality, and problem. For the positive factorial polarity, it produces a test value for the no communication mode of 19.34 and for the modality face-to-face of 9.25 , referring lemmas such as to pay, to betray, email, and psychotherapist.

\section{Therapist's feelings regarding the dropout}

The correspondence analysis for the therapist's feelings variable showed two factors explaining respectively $34.93 \%$ and $32.98 \%$ of the data variance (Figure 3). With respect to the horizontal axis, the negative factorial polarity produces a test value for sadness of -16.72 and -14.30 for sense of impotence, referring lemmas such as to contact, to mistreat, trauma, and young; for the positive factorial polarity the value of anger test is 28.87 , referring lemmas such as anger, to pay, to devalue, and to upset. With respect to the vertical axis, the negative factorial polarity produces a test value of -27.86 for relief, referring lemmas such as dependency, unpleasant, diagnosis, and to send; for the positive factorial polarity it produces a test value sadness of 11.53 and for anger of 9.25 , referring lemmas such as to devalue, anger, trauma, and trust.

\section{Specificity analysis}

The specificity analysis, performed for the therapist's narcissism, revealed that the prevailing feelings of the therapist regarding the dropout were for Group A of sadness, while for Group B of relief, anger and a sense of impotence. Table 2 shows the results relative to Group A and Group B compared to the typical lexical units; the first ten significant headings are listed with the chi - square (threshold value $\chi^{2}=3.84, \mathrm{df}=1, \mathrm{P}<0.05$ ) for each group.

\section{Discussion}

The dropout is a frequent occurrence that every psychotherapist has faced. There are various ways to deal with it. Generally speaking, our results indicate that some psychotherapists have reflected much on their mistakes and retraced the whole path taken with the patient, others turned to colleagues requesting supervision, and others have reconsidered the quality of the close therapeutic alliance with the patient. Indeed, the dropout experience activates specific emotional reactions, mainly characterized by devaluation or angry feelings, and leave a significant reminiscence in the therapist.

More in detail, the cluster analysis conducted in the present study confirms that the therapeutic alliance plays a fundamental role in the development or in the premature termination of the treatment (Safran \& Muran, 1998; Safran, Segal, Shaw, \& Vallis, 1990). Cluster 4, labeled Therapeutic alliance and relationship explains the $27 \%$ of the variance. It seems a trans-theoretical factor not influenced by the therapist orientations. Cluster 2, labelled Therapist's subjective experience, refers to the other important aspects implicated in the premature termination of the treatment. It explains the $30 \%$ of the variance suggesting an important part played by the specific emotional reactions of the therapist (Maggio, Molgora, \& Oasi, 2019; Tanzilli, Muzi, Ronningstam, \& Lingiardi, 2017). In particularly, already in cluster 1 we have found lemmas such as mistake, frustration, interruption, that lead us to think that the psychotherapist perceives the experience of the dropout as a turning point, without the possibility to

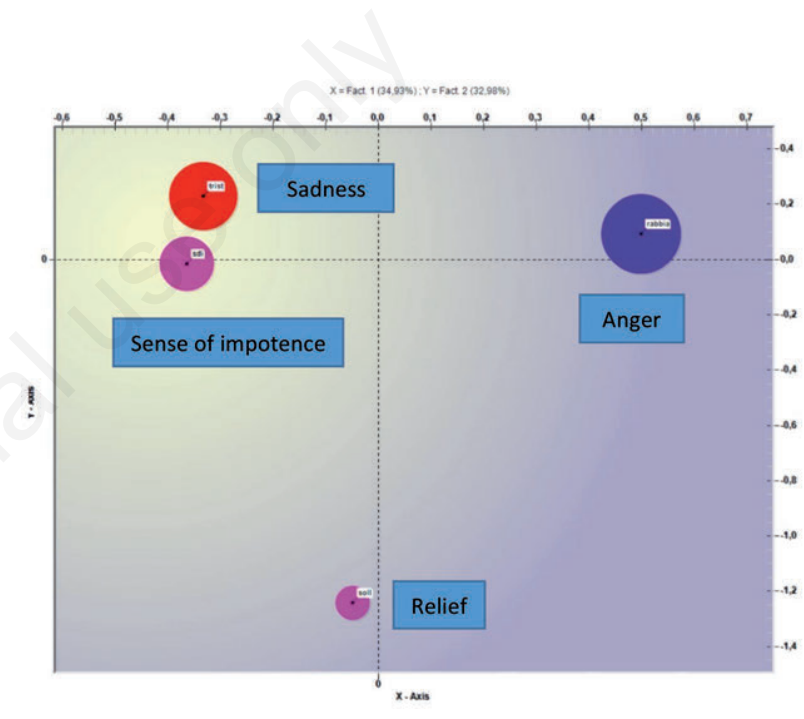

Figure 3. Correspondence analysis: therapist's feelings regarding the dropout.

Table 2. Specificity analysis: lemmas by group.

\begin{tabular}{llll}
\hline \multicolumn{1}{c}{ Group A } & \multicolumn{2}{c}{ Group B } \\
\hline Lemma & CHI & Lemma & $C H I^{2}$ \\
\hline Message & 16.38 & I & 16.73 \\
\hline Effort & 11.24 & To pay & 10.89 \\
\hline To success & 10.57 & Therapist & 8.84 \\
\hline Difficulty & 8.03 & Carry on & 7.10 \\
\hline Certainty & 8.01 & To exit & 7.10 \\
\hline Couple & 7.48 & Year & 7.10 \\
\hline Drugs & 6.54 & Thing & 6.97 \\
\hline Question & 5.68 & Countertransference & 6.85 \\
\hline Partner & 5.58 & Man & 6.16 \\
\hline To bring & 5.56 & Type & 6.16 \\
\hline
\end{tabular}


start over his job with that specific patient. This failure elicits probably different effects: an adequate and rational reaction, connected with the cluster 3 and linked to the supervision situation and its goal (Ogden, 2005). The therapist wishes better knowledge and understanding of the possible reasons of the dropout. Next to this, a specific feeling, reported in the lemmas gathered in cluster 2, such as to feel, anger, to betray, to mistreat, to forget, and that have to be reconnected to a specific dropout situation. In other words, the cluster analysis shows both elements related to the dropout situation, in particular with respect to the management of the therapeutic alliance, and to the purely emotional sphere. Finally, the implication of the introduction of the pharmacotherapy or of the other external intervention like psychiatric consultation in treatment is remarkable and well highlighted in the results of cluster 4 (see terms such as drugs, symptom).

We can also suppose, according to Stone (1961) and to Henry and Strupp (1994), that the emotional reaction of the therapist is related to his mental condition and that the dropout cases could elicit or could mark some unsolved relationship problems in the therapist. In particular, considering the narcissistic dimension of the therapist, the analysis of the distribution of the 4 clusters among the different levels of these dimensions show that an average level of narcissism allows a better sensitivity towards the therapeutic alliance and the relationship. The delta value is remarkable: $21.7 \%$ for group $\mathrm{A}$ in comparison to $29.1 \%$ for group B from cluster 4 . Although the results related to narcissism are not enough to prove the existence of a cause-effect relationship between the presence of the therapist's narcissistic traits and the higher or lower rate of therapeutic failures, it is possible to notice a trend line. We refer to the greater sensitivity towards feelings of sadness in psychotherapists who have low levels of narcissism (covert) emerged in the specificity analysis. This confirms that psychotherapeutic is an emotionally demanding kind work. In turn, this could endanger the psychic balance of narcissistically vulnerable clinicians or, in contrast, increase defensive narcissistic attitudes (Gale, Hawley, Butler, Morton, \& Singhal, 2016; West, Dyrbye, Erwin, \& Shanafelt, 2016).

Compared to the variety of emotional reactions (sadness, sense of impotence, anger, and relief), the correspondence analysis shows a contrast between psychodynamic approach and cognitive-behavioural/other approaches. Typical lemmas of psychodynamic approach are disappointment, need, desire, countertransference, and psychotherapist; on the contrary, typical lemmas of cognitive-behavioural/other approaches are goal, challenge, treatment, and patient. The meaning of these different key words leads us to two different perspectives for reading the situation: one more focused on the conductor of the treatment and on his mind; the other more focused on the psychotherapeutic situation and its technical problem. This result supports the hypothesis that the psy- chotherapist's orientation could be kept into consideration as predictive reaction in front of dropout cases and could cause a specific emotional reaction in relationships with difficult patients (Roos \& Werbart, 2013) or in front of a different psychopathology (Lopes, Gonçalves, Sinai, \& Machado, 2015; Swift \& Greenberg, 2014). Through the correspondence analysis we can also suppose that the method of interruption of treatment is tested in different ways within a continuum that goes from to devaluate to to happen by each therapist. In any case, the dropout case represents an important event in the clinical practitioner.

\section{Conclusions}

Some limitations may be found in this study. First, the small sample as well as the sample recruitment process: the psychotherapists who decided to take part could have probably a less negative experience of their failure. Furthermore, we have distinguished the psychodynamic and the cognitive-behavioural orientations, putting together all other approaches. Further research is needed to better understand the specificity of different orientations. Another limit is due to the dropout case is a past event on which memory bias is unavoidable and hardly insurmountable. Future studies should assess whether these findings are confirmed, controlling, for example, for the timing in which dropout (the last?) occurred and how many dropouts have been experienced by the therapist. Finally, although the therapist's point of view is usually less investigating, and this represents a value of the present work, it would also be desirable to investigate the patient's point of view, to check convergences or divergences from the psychotherapist's one. All these elements do not permit to generalize the affirmation reported above and more extensive studies will have to be made to support our findings.

\section{References}

Atwood, G. E., Stolorow, R. D., \& Trop, J. L. (1989). Impasses in psychoanalytic therapy: A royal road. Contemporary Psychoanalysis, 25(4), 554-573. doi: 10.1080/00107530.1989. 10746320

Berk, M., \& Parker, G. (2009). The elephant on the couch: sideeffects of psychotherapy. Australian \& New Zealand Journal of Psychiatry, 43(9), 787-794.

Boisvert, C. M., \& Faust, D. (2006). Practicing psychologists' knowledge of general psychotherapy 751 research findings: Implications for science-practice relations. Professional Psychology: Research and Practice, 37(6), 708-716. doi: 10.1037/0735-7028.37.6.708

Elkind, S. N. (1992). Resolving impasses in therapeutic relationship. New York: Guilford Press.

Flückiger, C., Del Re, A. C., Wampold, B. E., \& Horvath, A. O. (2018). The alliance in adult psychotherapy: A meta-analytic synthesis. Psychotherapy, 55(4), 316-340. doi: 10.1037/ pst0000172

Fossati, A., Borroni, S., Grazioli, F., Dornetti, L., Marcassoli, I., 
Maffei, C., \& Cheek, J. (2009). Tracking the hypersensitive dimension in narcissism: Reliability and validity of the Hypersensitive Narcissism Scale. Personality and Mental Health, 3, 235-247. doi: 10.1002/pmh.92

Frayn, D. H. (1992). Assessment factors associated with premature psychotherapy termination. American Journal of Psychotherapy, 46(2), 250-261.

Gale, T. M., Hawley, C. J., Butler, J., Morton, A., \& Singhal, A. (2016). Perception of suicide risk in mental health professionals. PloS One, 11(2), 1-12. doi: 10.1371/journal. pone.0149791

Garfield, S. L. (1986). Research on client variables in psychotherapy. In S. L. Garfield \& A. E. Bergin (Eds.), Handbook of psychotherapy and behavior change (3rd ed., pp. 213-256). New York, NY: Wiley.

Grunebaum, H. (1986). Harmful psychotherapy experience. American Journal of Psychotherapy, 40(2), 165-176.

Heinonen, E., \& Nissen-Lie, H. A. (2019). The professional and personal characteristics of effective psychotherapists: a systematic review. Psychotherapy Research. Epub ahead of print. doi: 10.1080/10503307.2019.1620366

Hendin, H., \& Cheek, J. M. (1997). Assessing hypersensitive narcissism: A reexamination of Murray's Narcism Scale. Journal of Research in Personality, 31, 588-599. doi: 10.1006/jrpe.1997.2204

Henry, W. P., \& Strupp, H. H. (1994). The therapeutic alliance as interpersonal process. In A. O. Horvath \& L. S. Greenberg (Eds.), Wiley series on personality processes. The working alliance: Theory, research, and practice (pp. 51-84). Oxford, England: John Wiley \& Sons.

Hill, C. E., Nutt-Williams, E., Heaton, K. J., Thompson, B. J., \& Rhodes, R. H. (1996). Therapist retrospective recall impasses in long-term psychotherapy: A qualitative analysis. Journal of Counseling Psychology, 43(2), 207. doi: 10.1037/0022-0167.43.2.207

Horvath, A. O., Del Re, A. C., Flückiger, C., \& Symonds, D. (2011). Alliance in individual psychotherapy. Psychotherapy, 48(1), 9. doi: 10.1037/a0022186

Horvath, A. O., \& Symonds, B. D. (1991). Relation between working alliance and outcome in psychotherapy: A metaanalysis. Journal of Counseling Psychology, 38(2), 139. doi: 10.1037/0022-0167.38.2.139

Jarrett, C. (2007). When therapy causes harm. Psychologist, 21, 10-12.

Kächele, H., \& Schachter, J. (2014). On side effects, destructive processes, and negative outcomes in psychoanalytic therapies: Why is it difficult for psychoanalysts to acknowledge and address treatment failures? Contemporary Psychoanalysis, 50(1-2), 233-258. doi: 10.1080/00107530.2014.880321

Kazdin, A. E., \& Weiss, J. R. (Eds). (2003). Evidence-based psychotherapies for children and adolescents. New York, NY: Guilford Press.

Kohut, H. (1982). Introspection, empathy, and the semi-circle of mental health. International Journal of Psychoanalysis, $63,395-407$.

Lancia, F. (2004). Strumenti per l'analisi dei testi. Introduzione all'uso di T-lab. [Tools for text analysis. Introduction to T$l a b]$. Milano: Franco Angeli.

Linden, M. (2013). How to define, find and classify side effects in psychotherapy: from unwanted events to adverse treatment reactions. Clinical Psychology \& Psychotherapy, 20(4), 286-296. doi: 10.1002/cpp.1765

Lopes, R. T., Gonçalves, M. M., Sinai, D., \& Machado, P. P.
(2015). Predictors of dropout in a controlled clinical trial of psychotherapy for moderate depression. International Journal of Clinical and Health Psychology, 15(1), 76-80. doi: 10.1016/j.ijchp.2014.11.001

Maggio, S., Molgora, S., \& Oasi, O. (2019). Analyzing psychotherapeutic failures: A research on the variables involved in the treatment with an individual setting of 29 cases. Frontiers in Psychology, 10, 1250. doi: 10.3389/fpsyg.2019. 01250

Mays, D., \& Franks, C. (Eds.) (1985). Negative outcome in psychotherapy. New York, NY: Springer.

Miller, A. (1979). The drama of the gifted child and the psychoanalyst's narcissistic disturbance. International Journal of Psychoanalysis, 60(1), 47-58.

Miller, A. (2008). The drama of the gifted child: The search for the true self. New York, NY: Basic Books.

Mohr, D. C. (1995). Negative outcome in psychotherapy: A critical review. Clinical Psychology: Science and Practice, 2(1), 1-27. doi: 10.1111/j.1468-2850.1995.tb00022.x

Moos, R. H. (2005). Iatrogenic effects of psychosocial interventions for substance use disorders: prevalence, predictors, prevention. Addiction, 100(5), 595-604. doi: 10.1111/j.13600443.2005.01073.x

Mordecai, E. M. (1991). A classification of empathic failures for psychotherapists and supervisors. Psychoanalytic Psychology, 8(3), 251. doi: 10.1037/h0079282

Murray, H. A. (1938). Explorations in personality. New York, NY: Oxford University Press.

Nathan, P. E., \& Gorman, J. M. (1998). A guide to treatments that work. New York, NY: Oxford University Press.

Nathan, P. E., \& Gorman, J. M. (2007). A guide to treatments that work (3rd ed.). New York, NY: Oxford University Press.

Nathanson, D. L. (1992). The nature of therapeutic impasse. Psychiatric Annals, 22(10), 509-513. doi: 10.3928/00485713-19921001-07

Newirth, J. (1995). Impasses in the psychoanalytic relationship. In Session: Psychotherapy in Practice, 1(1), 73-80.

Ogden, T. H. (2005). On psychoanalytic supervision. International Journal of Psychoanalysis, 86(5), 1265-1280. doi: 10.1516/BEE8-C9E7-J7Q7-24BF

O'Keeffe, S., Martin, P., Goodyer, I. M., Wilkinson, P., Consortium, I., \& Midgley, N. (2018). Predicting dropout in adolescents receiving therapy for depression. Psychotherapy Research, 28(5), 708-721. doi: 10.1080/10503307. 2017.1393576

Omer, H. (1994). Critical interventions in psychotherapy: From impasse to turning point. New York, NY: WW Norton \& Co.

Pekarik, G. (1985). Coping with dropouts. Professional Psychology: Research and Practice, 16(1), 114-123. doi: 10.1037/0735-7028.16.1.114

Pulver, S. E. (1992). Impasses in psychodynamic psychotherapy. Psychiatric Annals, 22(10), 514-519. doi: 10.3928/00485713-19921001-08

Rhodes, R. H., Hill, C. E., Thompson, B. J., \& Elliott, R. (1994). Client retrospective recall of resolved and unresolved misunderstanding events. Journal of Counseling Psychology, 41(4), 473. doi: 10.1037/0022-0167.41.4.473

Ritter, K., Dziobek, I., Preissler, S., Rüter, A., Vater, A., Fydrich, T., ... Roepke, S. (2011). Lack of empathy in patients with narcissistic personality disorder. Psychiatry Research, 187(1-2), 241-247. doi: 10.1016/j.psychres. 2010.09.013

Roback, H. B. (2000). Adverse outcomes in group psychotherapy: 
Risk factors, prevention, and research directions. The Journal of Psychotherapy Practice and Research, 9(3), 113.

Roos, J., \& Werbart, A. (2013). Therapist and relationship factors influencing dropout from individual psychotherapy: A literature review. Psychotherapy Research, 23(4), 394-418. doi: 10.1080/10503307.2013.775528

Roth, A., \& Fonagy, P. (1996). What works for whom? New York, NY: Guilford Press.

Roth, A., \& Fonagy, P. (2004). What works for whom? (2nd ed.). New York, NY: Guilford Press.

Rubin, A., Dolev, T., \& Zilcha-Mano, S. (2018). Patient demographics and psychological functioning as predictors of unilateral termination of psychodynamic therapy. Psychotherapy Research, 28(5), 672-684. doi: 10.1080/ 10503307.2016.1241910

Safran, J. D., \& Muran, J. (Eds.). (1998). The therapeutic alliance in brief psychotherapy. Washington DC: American Psychological Association.

Safran, J. D., Segal, Z. V., Shaw, B. F., \& Vallis, T. M. (1990). Patient selection for short-term cognitive therapy. In J. D. Safran \& Z. V. Segal (Eds.), Interpersonal process in cognitive therapy (pp. 226-247). New York: Basic Books.

Savaresi, S., M., \& Booley, D., L. (2001). On the performance of bisecting K-means and PDDP, 1st SIAM Conference on Data Mining, Chicago.

Schwarzkopf, K., Straus, D., Porschke, H., Znoj, H., Conrad, N., Schmidt-Trucksäss, A., \& von Känel, R. (2016). Empirical evidence for a relationship between narcissistic personality traits and job burnout. Burnout Research, 3, 25-33.

Soygüt, G., \& Gülüm, İ. V. (2016). A thematic analysis of therapists' perspectives on therapeutic alliance rupture moments. Research in Psychotherapy: Psychopathology, Process and Outcome, 19(2). doi: 10.4081/ripppo.2016.235

Stein, A. (1972). Causes of failure in psychoanalytic psychotherapy. In B. Wolman (Ed.), Success and failure in psychoanalysis and psychotherapy (pp. 37-52). New York, NY: Macmillan.

Steinbach, M., Karypis, G., \& Kumar, V. (2000). A comparison of document clustering techniques. KDD Workshop on Text Mining, 400(1), 525-526.

Stella, S., \& Oasi, O. (1996). Motivazioni e identità dello studente di psicologia. Risultati di un'indagine in Università
Cattolica [Motivations and Identity of the Student in Psychology. Results from a Survey Carried Out in Catholic University]. Vita \& Pensiero, 1, 60-67.

Stone, L. (1961). The psychoanalytic situation: An examination of its development and essential nature. Oxford, England: International University Press.

Strupp, H. H. (1993). Lessons from psychotherapy research and practice. Paper presented at the 101st Annual Convention of the American Psychological Association, Toronto, Ontario, Canada.

Swift J. K., \& Greenberg, R. (2012). Premature discontinuation in adult psychotherapy: A meta-analysis. Journal of Consulting and Clinical Psychology, 80(4), 547-559, doi: 10.1037/a0028226

Swift, J. K., \& Greenberg, R. P. (2014). A treatment by disorder meta-analysis of dropout from psychotherapy. Journal of Psychotherapy Integration, 24(3), 193. doi: 10.1037/ a0037512

Swift, J. K., Spencer, J., \& Goode, J. (2018). Improving psychotherapy effectiveness by addressing the problem of premature termination: Introduction to a special section. Psychotherapy Research, 28(5-6), 669-671. doi: 10.1080/10503307.2018.1439192

Tanzilli, A., Muzi, L., Ronningstam, E., \& Lingiardi, V. (2017). Countertransference when working with narcissistic personality disorder: An empirical investigation. Psychotherapy, 54(2), 184-194. doi: 10.1037/pst0000111

Taylor, G. J. (1984). Psychotherapy with the boring patient. Canadian Journal of Psychiatry, 29(3), 217-222.

Watkins, C. E. (1983). Counselor acting out in the counseling situation: An exploratory analysis. Journal of Counseling \& Development, 61(7), 417-423.

Weiner, M. F. (1974). The psychotherapeutic impasse. Diseases of the Nervous System, 35(6), 258- 261.

West, C. P., Dyrbye, L. N., Erwin, P. J., \& Shanafelt, T. D. (2016). Interventions to prevent and reduce physician burnout: a systematic review and meta-analysis. Lancet, 388(10057), 2272-2281. doi: 10.1016/S0140-6736(16) 31279-X

Wierzbicki, M., \& Pekarik, G. (1993). A meta-analysis of psychotherapy dropout. Professional Psychology: Research and Practice, 24(2), 190-195. doi: 10.1037/0735-891 7028. 24.2.190 